\title{
A Glance into Regional Parkinson's Disease Characteristics: What Differs from Northwest to Southeast of Turkey?
}

\author{
Saadet Sayan ${ }^{1 *}$ (), Yıldız Degirmenci ${ }^{2}$ (), Dilcan Kotan ${ }^{3}$ (i) \\ ${ }^{1}$ Neurology Department, SB. Sakarya University of Training and Research Hospital, Sakarya, Turkey \\ ${ }^{2}$ Neurology Department, Faculty of Medicine, Duzce University, Duzce, Turkey \\ ${ }^{3}$ Neurology Department, Faculty of Medicine, Sakarya University, Sakarya, Turkey \\ Email:*dr_sdt.86@hotmail.com,ydegir@gmail.com,dilcankotan@yahoo.com
}

How to cite this paper: Sayan, S., Degirmenci, Y. and Kotan, D. (2020) A Glance into Regional Parkinson's Disease Characteristics: What Differs from Northwest to Southeast of Turkey? Neuroscience \& Medicine, 11, 63-73.

https://doi.org/10.4236/nm.2020.113008

Received: June 10, 2020

Accepted: August 30, 2020

Published: September 2, 2020

Copyright $\odot 2020$ by author(s) and Scientific Research Publishing Inc. This work is licensed under the Creative Commons Attribution International License (CC BY 4.0).

http://creativecommons.org/licenses/by/4.0/

\begin{abstract}
Introduction: Parkinson's disease (PD) is the second common neurodegenerative disease following Alzheimer's disease. Multifactorial risk factors including environmental, nutritional and genetic factors may affect the frequency, risks, and genetic features of PD in different geographic and ethnic regions. Background: Our aim was to investigate the sociodemographic and disease characteristics, cognitive performances of patients with PD in Nusaybin, a southeastern city, and Hendek a northwestern city which have different geographical-cultural status, and to investigate the possible effects of regional differences on disease characteristics. Method: This retrospective study includes the data of patients with the diagnosis of PD who presented to outpatient Neurology clinics of Hendek State Hospital which is a city in the northwestern region of Turkey between April 2017 and June 2018 and patients who presented to the outpatient Neurology clinics of Nusaybin State Hospital, which is a city in the southeastern region of Turkey between October 2015 and January 2017. SPSS.23c (Statistical package for Windows) database was used for statistical analysis. Results: Our study included 114 cases with Parkinson's disease in Hendek and 96 cases in Nusaybin.The majority of patients had idiopathic PD (IPD) in both provinces (96.9\% in Hendek, and $92.1 \%$ in Nusaybin). Educational status of female patients was significantly lower in Nusaybin when compared with Hendek (9.3\% and 63.3\%, respectively). Family history for IPD was significantly higher in Hendek than Nusaybin $(31.7 \%$ and $9.9 \%$, respectively). There was a positive correlation between educational status and cognitive performances of the patients in both groups. Negative correlation was found between standardized mini mental test (s-mmt) scores and stage, severity of IPD in both groups. Conclusion: The socio-cultural
\end{abstract}


status of our country decreases by going from west to east. Thus knowledge about PD, accessibility to the hospitals and health centers with the opportunity to get optimum treatments may show variabilities in between the regions. We believe that our study provides a comparison of patients with PD in two different regions of our country with different geographic, genetic characteristics, and development levels.

\section{Keywords}

Parkinson's Disease, Cognition, Epidemiology, Turkey

\section{Introduction}

Parkinson's disease (PD) is a progressive, hypokinetic movement disorder characterized by bradykinesia, rigidity, resting tremor, and postural instability [1]. The motor symptoms that occur among the clinical features may be accompanied by non-motor findings such as autonomic, cognitive, neuropsychiatric symptoms, and sleep-related disorders [1] [2] [3].

Since PD is a chronic, neurodegenerative disease that leads to disability in due course of the disease [4]. Pathogenesis of PD is associated with retrograde neuronal destruction of mesostriatal dopaminergic pathway [5] [6] [7]. However, being a sporadic disease, it has a complex aetiology with the interactions of environmental factors and genetic predispositions [8]. Diagnosis of PD is based on clinical criteria described by International Movement Disorders Society [8]. The severity of the disease is determined by the unified Parkinson's disease rating scale (UPDRS) [9], and the stage is determined by the modified Hoehn Yahr scale (modified H\&Y) [10].

Since we believe that prevalence, risks, and transition pattern of the disease may vary according to geographic and ethnic regions, we aimed to investigate the clinical, cognitive and socio-demographic features of the patients of PD in two different regions of Turkey. These regions are two distinct cities. They are Nusaybin and Hendek which are located in the different geographic and socio-cultural regions of Turkey. Nusaybin is located in the southeast of Turkey and Hendek is a north western city. Regions display similar characteristics in terms of population density with socio-cultural differences. According to our knowledge and literature review, our study contributes favorable data to the literature by assessing the pwPD in terms of clinical, cognitive and socio-demographic features and comparing all these characteristics due the regional distribution.

\section{Methods}

Our study was approved by the local ethical committee of Sakarya University Faculty of Medicine with an approval number of 51 in 14.02.2018. In this retrospective and cross-sectional study, data of the pwPD who presented to the 
neurology outpatient clinic in Nusaybin between October 2015 and January 2017 was recruited retrospectively. The data of the pwPD in Hendek were recruited between April 2017 and June 2018.

The data of the patients who were diagnosed as Idiopathic Parkinson's Disease (IPD) and Parkinson-plus syndromes including progressive supranuclear palsy (PSP), multiple system atrophy (MSA), and Lewy body dementia (LBD) were recorded in the given time frames in these two regions. Patients with the aetiology of seconder parkinsonism were excluded via anamnesia and neuro-imaging. Sociodemographic features, family and medical history, and the features of Parkinson's disease (motor and non-motor clinical findings, duration of PD, severity of PD (according to the Unified Parkinson's Disease Rating Scale-III (UPDRS-III)) [9], and modified Hoehn \& Yahr stages (modified-H\&Y) [10]) were recorded.

Cognitive performance scores of the pwPD assessed by the Standardized Mini Mental Test (s-MMT) scores were of the pwPD were analysed [11] [12].

According to modified-H\&Y scores, the disease was divided into 5 stages as modified-H\&Y 1, 2 is graded as "early stage" and modified-H\&Y $\geq 3$ as "advanced stage" PD. According to s-MMT, the cognitive status of the pwPD were staged as follows; 24 - 30 points were accepted as "normal", 20 - 23 "mild", 10 19 "moderate" and 0 - 9 "advanced" stage [11] [12].

Statistical analysis was performed using the SPSS.23c statistical software program. Kolmogorov-Simirnov and Shapiro-Wilk tests were used to determine whether the distribution of data was normal or not. Descriptive statistics were expressed as mean \pm standard deviation if normal data were distributed normally, median and minimum maximum if not normal distribution, categorical variables were expressed as number of cases and percentage (\%). The homogeneity of the numerical data had normal distribution was examined by Levene's test. Homogeneous numerical data were compared with One-Way Anova and non-homogeneous data with Welch's test. Tukey test was used for post-hoc analysis. Numerical data without normal distribution were compared with Kruskal Wallis and Mann Whitney U test was used for subgroup analysis. Pearson Chi-Square test or Fischer Exact test was used to compare categorical data. The statistical significance level of the obtained data was interpreted with "p" value. $\mathrm{p}<0.05$ was considered statistically significant. On the correlation analysis, Spearman's test was used for normal distribution, if not Pearson test was used.

\section{Results}

Our study included 114 cases with Parkinson's disease (105 cases had IPD, 9 cases had plus syndrome) in Hendek and 96 cases (93 cases had IPD, 3 cases had Parkinson plus syndrome) in Nusaybin. Sociodemographic and chronic disease features of the patients are summarized in Table 1 . The average age of pwPD ( $n$ $=114)$ in the Hendek was $71.71(50-94)$, of which $50.9 \%(n=58)$ were female 
Table 1. Sociodemographic and chronic disease features of patients.

\begin{tabular}{|c|c|c|c|c|c|c|}
\hline & \multicolumn{3}{|c|}{ Hendek $(n=114)$} & \multicolumn{3}{|c|}{ Nusaybin $(n=96)$} \\
\hline \multicolumn{7}{|l|}{ Gender } \\
\hline Female (n(\%)) & \multicolumn{3}{|c|}{$58(50.9 \%)$} & \multicolumn{3}{|c|}{$45(46.9 \%)$} \\
\hline Male $(\mathrm{n}(\%))$ & \multicolumn{3}{|c|}{$56(49.1 \%)$} & \multicolumn{3}{|c|}{$51(53.1 \%)$} \\
\hline Hypertension & \multicolumn{3}{|c|}{$71(62.3 \%)$} & \multicolumn{3}{|c|}{$47(49 \%)$} \\
\hline Diabetes & \multicolumn{3}{|c|}{$22(19.2 \%)$} & \multicolumn{3}{|c|}{$22(22.9 \%)$} \\
\hline Coroner Artery Disease & \multicolumn{3}{|c|}{$15(13.2 \%)$} & \multicolumn{3}{|c|}{$10(10.4 \%)$} \\
\hline Cerebrovascular Disease & \multicolumn{3}{|c|}{$7(6.1 \%)$} & \multicolumn{3}{|c|}{$9(9.4 \%)$} \\
\hline Chronic Obstructive Pulmonary Disease & \multicolumn{3}{|c|}{$1(1 \%)$} & \multicolumn{3}{|c|}{-} \\
\hline Epilepsy & \multicolumn{3}{|c|}{$3(2.6 \%)$} & \multicolumn{3}{|c|}{$2(2 \%)$} \\
\hline Smoking & \multicolumn{3}{|c|}{$8(7 \%)$} & \multicolumn{3}{|c|}{-} \\
\hline Education status of IPH & Female $(\mathrm{n}(\%))$ & Male $(\mathrm{n}(\%))$ & $\operatorname{Sum}(\mathrm{n}(\%))$ & Female $(\mathrm{n}(\%))$ & Male $(\mathrm{n}(\%))$ & $\operatorname{Sum}(\mathrm{n}(\%))$ \\
\hline Illiterate & $18(17.7 \%)$ & $2(1.9 \%)$ & $20(19 \%)$ & $39(41.9 \%)$ & $19(20.4 \%)$ & $58(62.3 \%)$ \\
\hline Only literate & $9(8.5 \%)$ & $10(9.5 \%)$ & $19(18 \%)$ & $3(3.2 \%)$ & $19(20.4 \%)$ & $22(23.6 \%)$ \\
\hline Primary school (5 years) & $26(24.7 \%)$ & $28(26.6 \%)$ & $54(51.4 \%)$ & $1(1 \%)$ & $11(22 \%)$ & $12(12.9 \%)$ \\
\hline Middle School ( +3 years) & $0(0 \%)$ & $2(1.9 \%)$ & $2(1.9 \%)$ & $0(0 \%)$ & $0(0 \%)$ & $0(0 \%)$ \\
\hline High school (+3 years) & $1(0.9 \%)$ & $4(3.8 \%)$ & $5(4.7 \%)$ & $0(0 \%)$ & $0(0 \%)$ & $0(0 \%)$ \\
\hline University & $1(0.9 \%)$ & $4(3.8 \%)$ & $5(4.7 \%)$ & $0(0 \%)$ & $1(1 \%)$ & $1(1 \%)$ \\
\hline Sum & $55(52.3 \%)$ & $50(47.5 \%)$ & $105(100 \%)$ & $43(46.2 \%)$ & $50(53.7 \%)$ & $93(100 \%)$ \\
\hline
\end{tabular}

and $49.1 \%(\mathrm{n}=56)$ were male. The mean age of disease onset was $69(45-92)$ and the duration of illness was $25(1-360)$ months. The average age of pwPD (n $=96)$ in the Nusaybin was $70.86(47-93)$, of which $46.9 \%(n=45)$ were female and $53.1 \%(n=51)$ were male. Age of disease onset was $65.2(42-87)$, mean duration of illness was $37.4(1-480)$ months. Tremor was the dominant clinical feature of the patients in both provinces. The majority of patients, $96.9 \%$ ( $n=$ $105)$ in Nusaybin and $92.1 \%(n=93)$ in Hendek, had IPD others were diagnosed by Parkinson plus syndromes. De-novo pwIPD patients compromised $45.2 \%$ of the study group in Nusaybin and $80 \%$ in Hendek. Dominancy of gender was male in Nusaybin and female in Hendek. While the literacy level in Nusaybin was $29.2 \%$, it was $70.8 \%$ in Hendek ( $p<0.05$ ). Family history of IPD had in $9.9 \%$ of the cases in Nusaybin and $31.7 \%$ in Hendek $(\mathrm{p}<0.05)$. Pedigree analysis demonstrated that $50 \%(\mathrm{n}=4)$ of patients had an AR and $50 \%(\mathrm{n}=4)$ had an AD transition pattern.

The majority of patients were stage 2.5 according to modified-H\&Y staging in both provinces (Nusaybin 49.5\%, Hendek 46.7\%). There was no statistically 
significant difference between the provinces in terms of modified-H\&Y and UPDRS-III score levels of patients with IPD ( $\mathrm{p}>0.05)$.

In terms of cognitive performance, $43 \%$ of pwIPD had mild, $17.2 \%$ had moderate, $9.7 \%$ had severe cognitive impairment in Nusaybin, while $27.6 \%$ of patient with IPD had mild, $20 \%$ had moderate, $2.9 \%$ had severe cognitive impairment in Hendek. The percentage of patients with cognitive impairment was statistically significantly higher in Nusaybin than Hendek ( $\mathrm{p}$ < 0.05). (According to s-MMT, cognitive impairment was detected in $51.5 \%$ of cases in Hendek and $69.9 \%$ of cases in Nusaybin). Cognitive performance scores (s-MMT) of Nusaybin were lower than Hendek. There were no statistically significant differences in terms of performance scores $(p>0.05)$ between provinces.

Comprehensive disease features and additional complaints of the cases are displayed in Table 2, Table 3, and the distribution of severity of disease and cognitive impairment data are displayed in Table 4, Table 5.

Table 2. Clinical features of patients with Parkinson's disease.

\begin{tabular}{|c|c|c|}
\hline & Hendek $(n=114)(\%)$ & Nusaybin $(n=96)(\%)$ \\
\hline \multicolumn{3}{|l|}{ Clinical Dominance } \\
\hline Tremor & $101(88.6 \%)$ & $79(82.3 \%)$ \\
\hline Rigidity & $13(11.4 \%)$ & $17(17.7 \%)$ \\
\hline De-novo & $88(77.2 \%)$ & $43(44.8 \%)$ \\
\hline \multicolumn{3}{|l|}{ Types } \\
\hline İdiopathic Parkinson Disease & $105(88.6 \%)$ & $93(96.9 \%)$ \\
\hline Plus & $9(6.4 \%)$ & $3(3.1 \%)$ \\
\hline \multicolumn{3}{|l|}{ Family history } \\
\hline Autosomal dominant & $19(16.65 \%)$ & $4(4.15 \%)$ \\
\hline Autosomal recessive & $19(16.65 \%)$ & $4(4.15 \%)$ \\
\hline Gase limitation & $3(2.6 \%)$ & $3(3.1 \%)$ \\
\hline Dysphonia & $15(13.2 \%)$ & $9(9.3 \%)$ \\
\hline Amnesia & $44(38.6 \%)$ & $23(24 \%)$ \\
\hline Living dreams & $50(43.2 \%)$ & $27(28.1 \%)$ \\
\hline Hallucinations & $6(5.3 \%)$ & $8(8.3 \%)$ \\
\hline Constipation & $50(43.9 \%)$ & $27(28.1 \%)$ \\
\hline Hypersalivation & $41(36 \%)$ & $15(15.6 \%)$ \\
\hline Hot flashing & $22(19.3 \%)$ & $15(15.6 \%)$ \\
\hline Wobble & $64(56.1 \%)$ & $21(21.8 \%)$ \\
\hline Sleeping disorders & $23(20.2 \%)$ & $20(20.8 \%)$ \\
\hline Sum & $114(100 \%)$ & $96(100 \%)$ \\
\hline
\end{tabular}


Table 3. Clinical and demographic features of patients with Parkinson's disease.

\begin{tabular}{ccc}
\hline & Hendek $(\mathrm{n}=114)(\%)$ & Nusaybin $(\mathrm{n}=96)(\%)$ \\
\hline Age (years) ((med (min-max)) & $71.71(50-94)$ & $70.86(47-93)$ \\
Age of onset (years) ((med (min-max)) & $69(45-92)$ & $65.2(42-87)$ \\
Duration of disease (month) (med (min-max)) & $25(1-360)$ & $37.4(1-480)$ \\
Sum & 114 & 96 \\
\hline
\end{tabular}

Table 4. Distribution of patients with IPD by disease and cognitive impairment.

\begin{tabular}{|c|c|c|c|c|}
\hline & & Hendek (n(\%)) & Nusaybin (n(\%)) & p value \\
\hline \multirow{7}{*}{$\begin{array}{l}\text { Severity of Disease } \\
\text { (HOEHN\&YAHR) }\end{array}$} & Stage 1 & 0 & 0 & - \\
\hline & Stage 1.5 & $2(1.9 \%)$ & $6(6.5 \%)$ & $>0.05$ \\
\hline & Stage 2 & $9(8.6 \%)$ & $15(16.1 \%)$ & $>0.05$ \\
\hline & Stage 2.5 & 49 (46.7\%) & 46 (49.5\%) & $>0.05$ \\
\hline & Stage 3 & $30(28.6 \%)$ & $9(10.8 \%)$ & $<0.05$ \\
\hline & Stage 4 & $7(6.7 \%)$ & $10(10.8 \%)$ & $>0.05$ \\
\hline & Stage 5 & $8(7.5 \%)$ & $7(7.5 \%)$ & $>0.05$ \\
\hline \multirow{4}{*}{$\begin{array}{l}\text { Cognitive Performance } \\
\qquad(\mathrm{Mmt}-\mathrm{S})\end{array}$} & Normaly & $52(49.5 \%)$ & $28(30.1 \%)$ & \multirow{4}{*}{$<0.05$} \\
\hline & Mild & $29(27.6 \%)$ & $40(43 \%)$ & \\
\hline & Moderate & $21(20 \%)$ & $16(17.2 \%)$ & \\
\hline & Severe & $3(2.9 \%)$ & $9(9.7 \%)$ & \\
\hline
\end{tabular}

Table 5. Distribution of patients with IPD by UPDRS-III and cognitive performance test score.

\begin{tabular}{cccc}
\hline & Hendek & Nusaybin & p value \\
\hline UPDRS-III (mean \pm ss) & $42.64 \pm 18.08$ & $46.76 \pm 20.12$ & $>0.05$ \\
s-MMT (median (min-max) & $22.53 \pm 5.28$ & $21.53 \pm 6.98$ & $>0.05$ \\
\hline
\end{tabular}

There was a positive correlation between educational status and cognitive performance test scores in both provinces (Nusaybin $\mathrm{p}=0.015, \mathrm{r}=0.253$, Hendek; $\mathrm{p}<0.0001, \mathrm{r}=0.430$ ). There was a negative correlation between the disease stage and cognitive performance score in the Nusaybin (spearman $\mathrm{p}<0.0001, \mathrm{r}$ $=-0.416$ ), Hendek (spearman $\mathrm{p}=0.012, \mathrm{r}=-0.245$ ). There was a negative correlation between severity of disease and cognitive performance scores (s-MMT) in Nusaybin and Hendek provinces $(\mathrm{p}<0.01, \mathrm{r}=-0.526$ and $\mathrm{p}<0.01, \mathrm{r}=$ -0.420 , respectively). There was a positive correlation between IPD disease severity (UPDRS) and the duration of IPD in Nusaybin, whereas a positive corre- 
lation was found in the Hendek population $(\mathrm{p}=0.017, \mathrm{r}=0.248$, and $\mathrm{p}<0.01, \mathrm{r}$ $=0.259$, respectively).

\section{Discussion}

Parkinson's disease is a progressive neurodegenerative disease with characteristic motor and non-motor symptoms. The estimated prevalence of PD is $1 \%-2 \%$ in the population above 60 years, and $3.5 \%$ in the population between the ages of 85 to 89 [13] [14] [15]. This leads to a major cause of mortality and morbidity in aging populations. In our study, $23.7 \%(n=22)$ of patients were below the age of 65 , the age range was 65 to 84 years in $64.5 \%(n=60)$ of our patients, and $11.8 \%$ $(n=11)$ were at the age of above 85 , in Nusaybin. $13.3 \%(n=14)$ of patients were below the age of 65 , the age range was 65 to 84 years in $78.1 \%(n=82)$ of our patients, and $8.6 \%(n=9)$ were at the age of above 85 in Hendek.

There is a male tendency reported in the literature in pwIPD [16]. There was a female predominance $(\mathrm{n}=58,50.9 \%)$ in Hendek and male predominance $(\mathrm{n}=$ $51,53.1 \%)$ in Nusaybin. The educational status of female $(n=4,9.3 \%)$ was lower than male $(n=30,60 \%)$ in Nusaybin and female in Hendek $(n=26,47.3 \%)$.

The socio-cultural status is found to be relatively lower in Nusaybin province, which is a more rural and closed society in our country. The majority of patients with symptoms of parkinsonism were IPD in both provinces, $88.6 \%(n=105)$ in Hendek, 96.9\% $(n=93)$ in Nusaybin, in accordance with the literature [17].

Disease severity (UPDRS-III) score of pwIPD was $46.76 \pm 20.12$ in Nusaybin and $42.64 \pm 18.08$ in Hendek. Disease severity (UPDRS-III) of pwIPD was higher in Nusaybin but was not statistically significant ( $\mathrm{p}>0.05)$.

The majority of pwIPD were stage-3, 28.6\% $(n=30)$ in Hendek and 9.7\% $(n=$ 9) in Nusaybin, according to the modified-H\&Y score. Stage-3 pwIPD were significantly higher in Hendek $(\mathrm{p}<0.05)$. It can be associated with the differences of the provinces' disease awareness status, accessibility to the hospitals and health centers with the opportunity to get optimum treatments.

Epidemiologic studies are important about the awareness of disease and knowledge of publics, and play a pivotal role in improving public health. The prevalence of IPD is 111-202/100.000 according to regional epidemiologic studies on PD in our country [18] [19] [20] [21]. It is not possible to give clear information about the prevalence and incidence of the disease in our study because of the field study was not used and the study was performed only on the patients who presented to the hospital. However, IPD is more common in $\mathrm{Nu}$ saybin. The differences between regions could be related with factors such as nutritional habits (tea, coffee, milk, animal fat consumption differences), characteristics of rural life and genetic features [22].

The presence of sporadic and hereditary cases in PD points to the genetic aspect of the disease. It is an important risk factor, especially in young-onset cases. Genetic studies in recent years have described autosomal recessive (PARKIN (PRKN), PTEN induced kinase-1 (PINK1), protein degycase (DJ1), ATPase ca- 
tion transporting 13A2 (ATP13A2) and dominant transition patterns (synuclein alpha (SCNA) and leucine rich repeat kinase 2 (LRRK2) in PD [23].

Turkey is a country where consanguineous marriage is common, and a regional study reported the most common mutations with AR transition is PRKN gene mutations [24]. The transition pattern of cases with family history in our study was compatible with $\mathrm{AD}$ in $50 \%(\mathrm{n}=38)$ of Hendek and in $50 \%(\mathrm{n}=8)$ of Nusaybin and in the other half are AR. Regional genetic features of IPD can be achieved with advanced genetic studies to be planned on patients with different genetic transition patterns.

Cognitive impairment, a progressive clinical condition, is the most common cause of external dependency after motor findings of IPD. The prevalence of dementia in PD is $25 \%-30 \%$ [25] [26]. In a recent study, $47 \%$ of pwPD by normal cognitive performance had cognitive impairment after 6 months, and all of them within 5 years [27]. Clinical studies suggest that treatment of dementia decreases cognitive impairment in patients with PD. So, this demonstrates that early diagnosis and treatment are effective in maintaining independence in daily living activities.

In terms of cognitive performance, $43 \%$ of pwIPD had mild, $17.2 \%$ had moderate, $9.7 \%$ had severe cognitive impairment in Nusaybin, while $27.6 \%$ of patient with IPD had mild, $20 \%$ had moderate, $2.9 \%$ had severe cognitive impairment in Hendek. The percentage of patients with cognitive impairment was statistically significantly higher in Nusaybin than Hendek ( $\mathrm{p}<0.05$ ). (According to s-MMT, cognitive impairment was detected in $51.5 \%$ of cases in Hendek and $69.9 \%$ of cases in Nusaybin). We consider that the intensity of cognitive impairment in Nusaybin province is due to regional and genetic differences.

The cognitive performance test scores had a positive correlation with the educational status in both provinces in accordance with the literature, and a negative correlation with disease severity and disease stage (respectively; Nusaybin; $\mathrm{p}=0.015, \mathrm{r}=0.253$, Hendek; $\mathrm{p}<0.0001, \mathrm{r}=0.430$, Nusaybin; $\mathrm{p}<0.01, \mathrm{r}=$ -0.526 Hendek; $\mathrm{p}<0.01, \mathrm{r}=-0.420$, Nusaybin; $\mathrm{p}<0.0001, \mathrm{r}=-0.416$, Hendek; $\mathrm{p}=0.012, \mathrm{r}=-0.245$ ) [28] [29] [30] [31] [32]. In addition, the prevalence of dementia is higher than the literature in both provinces. This result may be associated with insufficiency in disease awareness and the delayed hospital admissions to the advanced stages of the disease.

Our study provides a comparison of pwIPD in two distinct regions of our country with different geographic and genetic backgrounds, revealing the genetic transition patterns, demonstrating disease awareness and risk factors strengthens our study. In addition, our study covers a long period of approximately 2.5 years in total and the evaluations are carried out by the same specialist physician in both centers are the considerable side of our study.

The weakness of our study are the planning was not field-based and examination of cases through hospital admissions, the data couldn't be generalized to the whole universe, lack of simultaneous evaluations on both samples, being con- 
ducted in different centers are as time and hospital bias. In addition, the lack of genetic analysis of individuals with a family history led to limited data.

\section{Conclusion}

Our study provided a comparison of pwPD in two different regions of our country with different geographic and genetic characteristics and contributing to the epidemiological data of our country. Developmental and educational status is decreased by going from west to east in our country. Thus, awareness of PD and accessibility to the health center for optimum treatments are inadequate in Nusaybin, in southeast. The social studies to call attention to PD may support the solution of problem. Consanguineous marriage is common in southeastern of our country. So, regional genetic features of IPD can be achieved with advanced genetic studies to be planned on patients with different genetic transition patterns.

\section{Conflicts of Interest}

The authors declare no conflicts of interest regarding the publication of this paper.

\section{References}

[1] Hughes, A.J., Daniel, S.E., Kilford, L. and Lees, A.J. (1992) Accuracy of Clinical Diagnosis of Idiopathic Parkinson's Disease. A Clinico-Pathological Study, of 100 Cases. Journal of Neurology, Neurosurgery, and Psychiatry, 55, 181-184. https://doi.org/10.1136/jnnp.55.3.181

[2] Chaudhuri, K.R., Healy, D.G. and Schapira, A.H. (2006) Non-Motor Symptoms of Parkinson's Disease: Diagnosis and Management. The Lancet Neurology, 5, 235-245. https://doi.org/10.1016/S1474-4422(06)70373-8

[3] Lim, S.Y. and Lang, A.E. (2010) The Nonmotor Symptoms of Parkinson's Disease: An Overview. Movement Disorders, 25, S123-S130. https://doi.org/10.1002/mds.22786

[4] Dorsey, E.R., Constantinescu, R., Thompson, J.P., Biglan, K.M., Holloway, R.G., et al. (2007) Projected Number of People with Parkinson Disease in the Most Populous Nations, 2005 through 2030. Neurology, 68, 384-386. https://doi.org/10.1212/01.wnl.0000247740.47667.03

[5] Kieburtz, K. and Wunderle, K.B. (2013) Parkinson's Disease: Evidence for Environmental Risk Factors. Movement Disorders, 28, 8-13. https://doi.org/10.1002/mds. 25150

[6] Racette, B.A. and Willis, A.W. (2015) Time to Change the Blind Men and the Elephant Approach to Parkinson disease. Neurology, 85, 190-196. https://doi.org/10.1212/WNL.0000000000001739

[7] Covy, J.P. and Giasson, B.I. a-Synuclein, Leucine-Rich Repeat Kinase-2, and Manganese in the Pathogenesis of Parkinson Disease. Neuro Toxicology, 32, 622-629. https://doi.org/10.1016/j.neuro.2011.01.003

[8] Postuma, R.B., Berg, D., Stern, M., Poewe, W., Olanow, C.W., et al. (2011) MDS Clinical Diagnostic Criteria for Parkinson's Disease. Movement Disorders, 30, 1591-1601. https://doi.org/10.1002/mds.26424 
[9] Goetz, C.G., Fahn, S., Martinez-Martin, P., Poewe, W., Sampaio, C., et al. (2007) Movement Disorder Society-Sponsored Revision of the Unified Parkinson's Disease Rating Scale (MDS-UPDRS): Process, Format, and Clinimetric Testing Plan. Movement Disorders, 22, 41-47. https://doi.org/10.1002/mds.21198

[10] Hoehn, M.M. and Yahr, M.D. (1967) Parkinsonizm: Onset, Progression and Mortality. Neurology, 17, 427-442. https://doi.org/10.1212/WNL.17.5.427

[11] Folstein, M.F., Folstein, S.E. and McHugh, P.R. (1975) “Mini-Mental State": A Practical Method for Grading the Cognitive State of Patients for the Clinician. Journal of Psychiatric Research, 12, 189-198. https://doi.org/10.1016/0022-3956(75)90026-6

[12] Güngen, C., Ertan, T., Eker, E., Yaşar, R. and Engin, F. (2002) Reliability and Validity of the Standardized Mini Mental State Examination in the Diagnosis of Mild Dementia in Turkish Population. Turkish Journal of Psychiatry, 13, 273-281.

[13] de Rijk, M.C., Tzourio, C., Breteler, M.M., Dartigues, J.F., Amaducci, L., et al. (1997) Prevalence of Parkinsonism and Parkinson's Disease in Europe: The EUROPARKINSON Collaborative Study. European Community Concerted Action on the Epidemiology of Parkinson's Disease. Journal of Neurology, Neurosurgery, and Psychiatry, 62, 10-15. https://doi.org/10.1136/jnnp.62.1.10

[14] Twelves, D., Perkins, K.S.M. and Counsell, C. (2003) Systematic Review of Incidence Studies of Parkinson's Disease. Movement Disorders, 18, 19-31.

https://doi.org/10.1002/mds.10305

[15] de Lau, L.M.L. and Breteler, M.M.B. (2006) Epidemiology of Parkinson's Disease. The Lancet Neurology, 5, 525-535. https://doi.org/10.1016/S1474-4422(06)70471-9

[16] Gillies, G.E., Pienaar, I.S., Vohra, S. and Qamhawi, Z. (2014) Sex Differences in Parkinson's Disease. Frontiers in Neuroendocrinology, 35, 370-384. https://doi.org/10.1016/j.yfrne.2014.02.002

[17] Keener, A.M. and Bordelon, Y.M. (2016) Parkinsonism. Seminars in Neurology, 36, 330-334. https://doi.org/10.1055/s-0036-1585097

[18] Özbek, S.Z.M., Karlı, N., Özçakır, A., Yıldız, D. and Aslan, D. (2009) A Population-Based Survey to Determine the Prevalence of Movement Disorders in Orhangazi District of Bursa, Turkey. Turkish Journal of Neurology, 15, 109-118.

[19] Bolayır, E.T.A., Topalkara, K., Akyüz, A. and Topaktas, S. (2002) Sivas İl Merkezinde Parkinson Hastalığı Prevalansı. Çukurova Üniversitesi Tıp Fakültesi Dergisi, 24, 65-68.

[20] Torun, S., Uysal, M., Gücüyener, D. and Özdemir, G. (1995) Parkinson’s Disease in Eskişehir, Turkey. European Journal of Neurology, 2, 44-45.

[21] Durmus, H., Gokalp, M.A. and Hanagasi, H.A. (2015) Prevalence of Parkinson's Disease in Baskale, Turkey: A Population Based Study. Neurological Sciences, 36, 411-413. https://doi.org/10.1007/s10072-014-1988-x

[22] Seidl, S.E., Santiago, J.A., Bilyk, H. and Potashkin, J.A. (2014) The Emerging Role of Nutrition in Parkinson's Disease. Frontiers in Aging Neuroscience, 6, 36. https://doi.org/10.3389/fnagi.2014.00036

[23] Lesage, S. and Brice, A. (2009) Parkinson's Disease: From Monogenic Forms to Genetic Susceptibility Factors. Human Molecular Genetics, 18, R48-R59. https://doi.org/10.1093/hmg/ddp012

[24] Lohmann, E., Dursun, B., Lesagec, S., Hanagasi, H.A., Sevinc, G., et al. (2012) Genetic Bases and Phenotypes of Autosomal Recessive Parkinson Disease in a Turkish Population. European Journal of Neurology, 19, 769-77. https://doi.org/10.1111/j.1468-1331.2011.03639.x 
[25] Riedel, O., Klotsche, J., Spottke, A., Deuschl, G., Förstl, H., et al. (2008) Cognitive Impairment in 873 Patients with Idiopathic Parkinson's Disease. Results from the German Study on Epidemiology of Parkinson's Disease with Dementia (GEPAD). Journal of Neurology, 255, 255-264. https://doi.org/10.1007/s00415-008-0720-2

[26] Riedel, O., Klotsche, J., Spottke, A., Deuschl, G., Förstl, H., et al. (2010) Frequency of Dementia, Depression, and Other Neuropsychiatric Symptoms in 1,449 Outpatients with Parkinson's Disease. Journal of Neurology, 257, 1073-1082. https://doi.org/10.1007/s00415-010-5465-Z

[27] Pigott, K., Rick, J., Xie, S.X., Hurtig, H., Chen-Plotkin, A., et al. (2015) Longitudinal Study of Normal Cognition in Parkinson Disease. Neurology, 85, 1276-1282. https://doi.org/10.1212/WNL.0000000000002001

[28] Pai, M.C. and Chan, S.H. (2001) Education and Cognitive Decline in Parkinson's Disease: A Study of 102 Patients. Acta Neurologica Scandinavica, 103, 243-247.

[29] Mamikonyan, E., Moberg, P.J., Siderowf, A., Duda, J.E., Have, T.T., et al. (2009) Mild Cognitive Impairment Is Common in Parkinson's Disease Patients with Normal Mini-Mental State Examination (MMSE) Scores. Parkinsonism \& Related Disorders, 15, 226-231. https://doi.org/10.1016/j.parkreldis.2008.05.006

[30] Hawkes, C.H., del Tredici, K. and Braak, H. (2010) A Timeline for Parkinson's Disease. Parkinsonism \& Related Disorders, 16, 79-84. https://doi.org/10.1016/j.parkreldis.2009.08.007

[31] Meireles, J. and Massano, J. (2012) Cognitive Impairment and Dementia in Parkinson's Disease: Clinical Features, Diagnosis, and Management. Frontiers in Neurology, 3, 88. https://doi.org/10.3389/fneur.2012.00088

[32] Xu, Y., Yang, J. and Shang, H. (2016) Meta-Analysis of Risk Factors for Parkinson's Disease Dementia. Translational Neurodegeneration, 5, Article No. 11. https://doi.org/10.1186/s40035-016-0058-0 